\title{
CELEBRANDO OS CENTENÁRIOS INACIANOS
}

\author{
Celebrating the Ignatian Centenaries
}

\author{
Alfredo Sampaio Costa * \\ Rossano Zas Friz de Col **
}

A Companhia de Jesus celebra nesse ano de 2021/2022 dois centenários: os 500 anos da ferida de Inácio na batalha de Pamplona e os 400 anos da canonização de Inácio e convida a todos e todas a celebrarem com ela a oportunidade de caminharmos também para uma maior conversão e transformação interior ao serviço de Deus na Igreja. O tema escolhido para esse ano inaciano é muito inspirador: "Ver novas todas as coisas em Cristo". Refere-se à experiência de iluminação espiritual que Inácio teve às margens do Rio Cardoner, em Manresa, que ele conta na sua Autobiografia (n. 30).

Fazer memória desses acontecimentos é um convite e também um desafio a buscarmos, hoje, uma nova sensibilidade teológica, a não nos contentarmos com olhares cansados e rotineiros, mas buscando sempre aprender a ver com olhos novos a realidade. Em tempos de polarizações, onde vemos crescer a intolerância em todos os âmbitos da sociedade e da Igreja, o convite ao diálogo, presente na Fratelli tutti de Francisco, encarna esse ideal de sempre buscar o "maior serviço", que traduz o magis inaciano.

No seu livro "A caminho com Inácio", o Padre Geral dos Jesuítas, Padre Arturo Sosa, afirma que a maior contribuição de Santo Inácio para a Igreja e para a sociedade foi sua visão universal e de longo prazo. "Ele foi capaz

\footnotetext{
* Faculdade Jesuíta de Filosofia e Teologia, Belo Horizonte, Minas Gerais, Brasil.

* Jesuit School of Theology of Santa Clara University, Berkeley, California, United States.
} 
de ver para além dos acontecimentos imediatos, para se projetar mais à frente na história [...]. Em Inácio, essa capacidade está estreitamente ligada à sua experiência de Deus. Soube sair de si mesmo e se colocar numa perspectiva trinitária" (SOSA, 2021, p. 23).

Nessa perspectiva, Inácio foi aprendendo a articular experiência e reflexão a fim de testemunhar sua transformação/conversão pela graça do amor recebida. Foi um teólogo da experiência, não só pelo seu vivido, mas também por ter concebido, nos seus "Exercícios Espirituais", um itinerário para podermos ver todas as coisas de um modo novo, a partir de uma relação com o Senhor impregnada pelo amor recíproco.

\section{Em busca de uma teologia que brote da autêntica experiência espiritual}

Este número da Perspectiva Teológica quer mostrar como a Tradição inaciana e a Teologia podem sair ambas enriquecidas de uma interação franca entre si. Que tipo de Teologia brota da experiência espiritual e de que forma a reflexão teológica protege a experiência espiritual dos enganos fáceis do sentimentalismo e alienação?

Guillermo Randle já insistia sobre a importância de uma teologia experiencial: a experiência de que se trata na Teologia e na Espiritualidade não é simplesmente afetiva (excluindo o conhecimento) ou puramente subjetiva ou imanente (excluindo a objetividade da Transcendência). Constitui-se como uma estrutura da consciência pessoal em sua abertura ao mundo, aos outros e a Deus. Neste sentido, todo o vivido desde o interior de Cristo, autenticamente e na fé, é de tipo experiencial, isto é, plenamente pessoal.

No âmbito da celebração dos 500 anos da conversão de Santo Inácio a teologia espiritual é especialmente interpelada, pois ela se define como a reflexão interdisciplinar sobre a transformação pessoal que produz a experiência da revelação cristã. Experiência na qual o Mistério de Deus se faz perceptível humanamente, pois busca sua criatura para lhe comunicar seu amor e aguardar por sua resposta, uma vez que só o amor correspondido transforma.

\section{Espiritualidade inaciana, surgida a partir de uma crise: fazer teologia em tempos de pandemia}

Seguimos enfrentando os efeitos devastadores da pandemia em todos os setores da vida humana. Os centenários inacianos ao nos remeter à ferida de Pamplona mostram como a espiritualidade inaciana é gestada 
em meio à crise e a dor. É cada vez mais urgente refletir sobre a situação hermenêutica em relação à Covid 19: uma nova compreensão que nos leve à necessidade de refazer relações e abrir-nos a uma realidade de esperança, a partir da fé.

O Instituto Humanitas Unisinos publicou recentemente o mapeamento "Saúde da Mente e Nova Realidade", conduzido pela NOZ Pesquisa e Inteligência em parceria com o Instituto Bem do Estar, realizado entre maio de 2020 e abril de 2021 com 1.515 participantes (primeira etapa) e 1.050 (segunda etapa). A pesquisa investigou o impacto do isolamento social no cotidiano do brasileiro, revelando que o medo, a depressão, a ansiedade nos bombardeiam por todos os lados ${ }^{1}$.

A espiritualidade inaciana nos convida a contemplar a dor, o sofrimento e a realidade da morte, fazendo-nos acompanhar a entrega amorosa do Senhor que faz surgir Vida da morte. Surge assim uma teologia que irradia compaixão e solidariedade, vencendo o fatalismo e a resignação.

\section{Como caminhar entre as "sombras de um mundo fechado"}

O Papa Francisco abre a encíclica Fratelli tutti descortinando um panorama que se apresenta sombrio: conflitos, medo, pandemias, violência, desinformação etc. (n. 9 a 53), para em seguida afirmar que "apesar dessas sombras densas que não se devem ignorar, desejo dar voz a diversos caminhos de esperança" (n. 54). "Convido à esperança que nos fala de uma realidade cuja raiz está no mais fundo do ser humano, independentemente das circunstâncias concretas e dos condicionamentos históricos em que vive" (n. 55). Não nos deixemos enganar pelo desânimo e pelo cansaço.

\section{Uma espiritualidade e teologia leiga e feminina}

Outro elemento importante a resgatar nesse diálogo entre a Teologia e a Espiritualidade Inaciana é o caráter marcadamente leigo da espiritualidade inaciana, como bem mostrou Carlos Cabarrús em um seu escrito sobre a inacianidade. O leigo Inácio de Loyola viveu e escreveu os Exercícios Espirituais. Hoje mais e mais leigos e leigas descobrem e se apaixonam por esse itinerário de vida espiritual. O caráter laical abre perspectivas novas também para a reflexão teológica. Cada vez mais as mulheres assumem o protagonismo seja

\footnotetext{
${ }^{1}$ INSTITUTO HUMANITAS UNISINOS. Pesquisa investiga o impacto da pandemia nas emoções dos brasileiros. Revista IHU on-line, São Leopoldo, 02 jul. 2021: Disponível em: http://www.ihu.unisinos.br/78-noticias/610715-pesquisa-investiga-o-impacto-da-pandemia-nas-emocoes-dos-brasileiros. Acesso em: 08 jun.2021.
} 
na promoção e divulgação da espiritualidade inaciana nos diversos Centros e Serviços de Espiritualidade e Centros Loyola de Fé e Cultura espalhados pelo nosso país, como também na pesquisa e reflexão teológica.

\section{O Discernimento como atitude de escuta do Espírito e como método de fazer teologia}

O Papa Francisco, como bom jesuíta, tem insistido na necessidade de sermos uma Igreja que escuta, que discerne e se coloca a serviço, deixando-se conduzir pelo Espírito. $\mathrm{O}$ discernimento espiritual é central na experiência espiritual de Inácio de Loyola e sua vida é pautada pela busca incessante da Vontade de Deus. Essa orientação perpassará a história nos seus seguidores.

O discernimento nos faz passar do já conhecido de certa maneira a um conhecimento mais profundo, a uma mudança radical de enfoque que nos ajuda a descobrir o revés da trama do superficial e anedótico, a olhar as coisas a partir de Deus, graças ao dom do seu Espírito que ilumina e permite ver o que antes se ignorava (RANDLE, 2013, p. 61).

França Miranda nos recorda que a espiritualidade inaciana é uma

“espiritualidade exigente que não aceita uma obediência infantil à autoridade nem submissão incondicional a princípios teóricos. Espiritualidade que deixa à pessoa a responsabilidade de buscar e achar continuamente a vontade de Deus ao longo de sua vida. Espiritualidade que supõe uma pessoa realmente madura e livre" (FRANÇA MIRANDA, 2018, p. 48).

\section{Caminhar como comunhão, superando polarizações exacerbadas}

Hoje um dos enormes desafios que enfrentamos como Igreja é caminhar como comunhão, superando polarizações exacerbadas que fomentam ódio e intolerância. A proposta da sinodalidade, tão cara ao Papa Francisco, põe em movimento um esforço de escuta e de abertura ao novo e ao diferente. Ela se traduz em serviços concretos à Igreja a partir da especificidade do carisma inaciano. Na reflexão teológica, essa busca conjunta dos caminhos do Espírito nas diferentes culturas é fundamental.

A espiritualidade inaciana, marcada pelo desejo de "sentir com e na Igreja" (EE, n. 352-370) nos coloca nesta perspectiva de abertura e diálogo.

A sinodalidade designa, antes de tudo, o estilo peculiar que qualifica a vida e a missão da Igreja, exprimindo a sua natureza como o caminhar juntos e o reunir-se em assembleia do povo de Deus convocado pelo Senhor Jesus 
na força do Espírito Santo para anunciar o Evangelho. Essa deve exprimir-se no modo ordinário de viver e operar da Igreja. Tal modus vivendi et operandi se realiza através da escuta comunitária da Palavra e da celebração da Eucaristia, da fraternidade da comunhão e da corresponsabilidade e participação de todo o povo de Deus, nos seus vários níveis e na distinção dos diversos ministérios e funções, na sua vida e na sua missão. (CTI, n. 70)

\section{Promover sempre mais o encontro e o diálogo, animados pela experiência espiritual de Inácio, inseridos numa cultura cada vez mais digital}

Estamos convencidos que é preciso levar adiante, também na relação Teologia-Espiritualidade, o que o Papa Francisco tanto insiste: promover sempre uma "cultura do encontro", onde uma saiba reconhecer o papel da outra, no respeito e aceitação recíprocos, mergulhados em uma cultura cada vez mais digital, com toda a riqueza de oportunidades de comunicação e encontro e também sabendo encarar suas ambiguidades e desafios.

Precisamente, para promover uma "cultura de encontro", aproveitando as facilidades de nossa era digital, quisemos ampliar o raio dos colaboradores a partir do horizonte inaciano, mostrando, na prática, como a reflexão sobre a experiência inaciana a partir de diferentes culturas pode ter peculiaridades próprias, mas sempre a serviço de uma mesma vocação compartilhada, que responde a um mesmo chamado. Somos de diferentes culturas, mas com uma mesma experiência e espiritualidade!

Que nesse Ano Inaciano, Espiritualidade inaciana e Teologia, na mesma busca de encontrar a Verdade em um encontro transformador e portador de esperança e salvação, possam sair enriquecidas e fortalecidas na sua missão própria, sabendo "ver novas todas as coisas em Cristo"!

\section{Siglas}

CTI = Comissão Teológica Internacional

$\mathrm{EE}=$ Exercícios Espirituais

\section{Referências}

COMISSÃO TEOLÓGICA INTERNACIONAL. A Sinodalidade na vida e na missão da Igreja. Disponível em:

https://www.vatican.va/roman_curia/congregations/cfaith/cti_documents/rc_cti_20180302_ sinodalita_po.html. Acessado em: 12 jul. 2021. 
FRANÇA MIRANDA, M. Igreja Sinodal. São Paulo: Paulinas, 2018.

FRANCISCO, Papa. Carta Encíclica Fratelli tutti - todos irmãos: sobre a fraternidade e a amizade social. São Paulo: Loyola, 2020.

INSTITUTO HUMANITAS UNISINOS. Pesquisa investiga o impacto da pandemia nas emoções dos brasileiros. Revista IHU on-line, São Leopoldo, 02 jul. 2021: Disponível em:

http://www.ihu.unisinos.br/78-noticias/610715-pesquisa-investiga-o-impacto-da-pandemia-nas-emocoes-dos-brasileiros. Acesso em: 08 jun. 2021.

RANDLE, G. Dar razón de Dios: un modo teológico ignaciano de proceder. Buenos Aires: San Benito, 2013.

SOSA, A. A Caminho com Inácio. São Paulo: Loyola, 2021.

Editorial submetido em 05.05.21 e aprovado em 04.08.21.

Alfredo Sampaio Costa SJ Doutor em Teologia pela Pontifícia Universidade Gregoriana (PUG, Roma - 2001) e professor do Programa de Pós-Graduação em Teologia da Faculdade Jesuíta de Filosofia e Teologia (FAJE). Orcid.org/0000-0003-3483-8082 E-mail: alfredosampaiosj@gmail.com

Endereço: Avenida Dr. Cristiano Guimarães, 2127

Planalto

31720-300 Belo Horizonte - MG

Rossano Zas Friz De Col SJ Doctor en teología y profesor de espiritualidad cristiana e ignaciana en la Jesuit School of Theology of Santa Clara University (Berkeley, California) y profesor invitado en la Pontificia Universidad Gregoriana (Roma). Orcid.org/0000-0003-42631591. E-mail: zasfriz.r@gesuiti.it

Dirección: 1735 Le Roy Avenue Berkeley, California

94709 United States 